\title{
Fossil arbuscular mycorrhizae from the Early Devonian
}

T. N. Taylor ${ }^{1}$

\section{Botany and Natural History Museum, University of Kansas, Lawrence, Kansas 66045}

W. Remy

H. Hass

H. Kerp

\section{Forschungsstelle fur Palaobotanik, Westfalische Wilhelms-Universitat, Miinster, Germany}

\begin{abstract}
The 400 million-year-old Rhynie chert has provided a wealth of information not only of early land plants, but also of the fungi that inhabited this paleoecosystem. In this paper we report the first unequivocal evidence of arbuscules in an endomycorrhizal symbiosis. A new genus, Glomites, is characterized by extraradical, aseptate hyphae with a two-parted wall, and an intraradical, highly branched network of thin-walled hyphae. Hyphal branches produce terminal, elongate-globose multilayered spores that lack a basal septum. Other hyphae penetrate cell walls and form arbuscules. Arbuscules are morphologically identical to those of living arbuscular mycorrhizae (AM) in consisting of a basal trunk and highly dichotomous distal branches that form a bush-like tuft. Arbuscules are confined to a narrow band of specialized thinwalled cells in the outer cortex that continue to be meristematic. Features of the fossil biotroph are compared with those of extant arbuscular mycorrhizae. Although interpretations regarding the evolution of mycorrhizal mutualisms continue to be speculative, the demonstration of arbuscules in the Early Devonian indicates that nutrient transfer is an ancient phenomenon that may have been in existence when plants invaded the land.
\end{abstract}

Key Words: arbuscule, biotrophs, Devonian, endomycorrhizae, fossil, Glomus, Glomites, mycorrhizae, mutualism, Rhynie chert

\section{INTRODUCTION}

One of the most significant events in the terrestrialization of plants was the evolution of biotrophic rootinhabiting symbioses. These interactions are generally

Accepted for publication April 20, 1995.

1 Author for correspondence. subdivided into seven major types based on the taxonomic group of fungi involved, and alterations in the mycobiont and roots that take place during the development of the mycorrhiza (Peterson and Farquhar, 1994). Of these, the most widely studied mycorrhizal system is the VAM-type (vesicular-arbuscular mycorrhiza), although some groups of these biotrophic endosymbionts do not produce vesicles. The primary benefit for the plant is the increase in phosphorus and nutrient uptake from the soil, although protection against certain soil pathogens, production of plant growth hormones and the increased solubility of soil minerals are also regarded as important benefits (Ahmadjian, 1986). In this symbiosis the mycobiont acquires carbon obligately from the host plant through the dichotomously branched, intraradical arbuscule.

The widespread occurrence of endomycorrhizae in most land plants has been one rationale used to suggest the antiquity of this mycorrhizal system (Trappe, 1987). More recently, the morphological similarity of fossil spores with the chlamydospores of living Glomus Tulasne \& Tulasne (Pirozynski and Dalpe, 1989), and sequence divergence data based on a molecular clock model (Simon et al., 1993) provide additional evidence for this hypothesis. Although several authors have speculated on the occurrence of endomycorrhizae associated with the roots and underground organs of fossil plants (e.g., Malloch et al., 1980; Nicolson, 1981), the only evidence to date includes nonseptate mycelium, coiled hyphae, thin-walled, slightly elongate spores interpreted as vesicles and chlamydospores (e.g., Kidston and Lang, 1921; Wagner and Taylor, 1984; Sharma et al., 1993). Until recently (Remy et al., 1994) the oldest structure that convincingly can be considered an arbuscule, the sine quine non of an endomycorrhizal symbiosis, comes from the Triassic of Antarctica (Stubblefield et al., 1987). Although there are several reports of Paleozoic arbuscules (e.g., Osborn, 1909; Halket, 1930), all have been demonstrated to be either artifacts or condensed cytoplasmic cell contents (Cridland, 1962). In this paper we describe the structure and organization of an endomycorrhizal fungus, including arbuscules, from the 400 millionyear-old Rhynie chert.

\section{MATERIALS AND METHODS}

The fossil fungus described here consists of hyphae, chlamydospores, and arbuscules that are distributed 
throughout aerial stems and rhizomes of Aglaophyton major Edwards (Edwards, 1986). Specimens were prepared by cementing pieces of the chert containing plants to standard microscope slides with Lakeside cement, and then selectively grinding the chert to a thickness of 50-150/j, $m$ using silicon carbide powder. All micrographs were prepared using oil immersion objectives directly on the polished surface of the rock. Slides are deposited in the Paleobotanical Collections of Professor Winfried Remy permanently deposited in the Forschungsstelle fur Palaobotanik, Westfalische Wilhelms-Universitat, Miinster, Germany. Acquisition numbers and types are noted in the figure descriptions and in the diagnosis.

\section{RESULTS}

Kidston and Lang (1921) used the generic name $\mathrm{Pa}$ laeomyces Renault for the spores and hyphae they described from the Rhynie chert. Their study encompasses a wide range of isolated fungal structures in which there was limited organic attachment among parts, and for which affinities and nutritional mode were conjectural. Although some details regarding the structure and morphology of this fungus remain unknown, we believe that there are sufficient characters available to propose the generic name Glomites for a fungus found in the chert with intraradical arbuscules. Palaeomyces will remain a generic name for other isolated spores and hyphae found in the chert.

\section{TAXONOMY}

Glomites Taylor, Remy, Hass et Kerp, gen. nov.

(Diagnosis same as for type species.)

\section{Glomites rhyniensis Taylor, Remy, Hass et Kerp, sp.} nov.

Extraradical, aseptate hyphae up to 25 ixn1 in diam, occasionally occurring in bundles, hyphal wall twoparted, rarely branched; intraradical hyphae of two types, one consisting of aseptate hyphae 8-14/mi in diam, thin-walled, extensively branched in hypodermis, branches produced in acute angles of $30-60^{\circ}$, occasionally with slight projections representing former site of deteriorated hyphae; other narrower hyphal branches produced at more right angles, narrow (5 льиі) and giving rise to solitary, occasionally multiple, terminal globose-elongate spores ranging from 50-80 $\mathrm{Mm}$; spore wall multilayered with inner layer continuous with subtending hypha, basal septum absent; other narrow hyphal branches penetrate cortical cell wall to form highly branched arbuscules, arbuscule with basal stalk approximately $211 \mathrm{~m}$ in diam, and forming fine distal tips, sometimes slightly swollen; arbuscules confined to narrow (one to four cells wide) outer cortical zone beneath hypodermis.

HOLOTYPE. Specimens in slide PB 1827 in the Paleobotanical Collection of Professor Winfried Remy permanently deposited in the Forschungsstelle fur Palaobotanik, Westfalische Wilhelms-Universitat, Miinster; FIG. 25 in this paper.

PARATYPES. Specimens in slide PB 1382, PB 1384, PB 1385, PB 1407, PB 1463, PB 1537, PB 1652, PB 1653, PB 1702, PB 1703, PB 1714, PB 1779, PB 1780, PB 1827, PB 1828, PB 2004, PB 2082 in the above collections; FIGS. 124, 26-39 in this paper.

Collection locality. Rhynie, Aberdeenshire, Scotland. National Grid Reference NJ 494276 (Edwards, 1986).

Age. Early Devonian.

Stratigraphic position. Siegenian.

Etymology. The generic name Glomites underscores the similarity to the extant genus Glomus; the ending ites is used to designate a fossil taxon, as discussed by Pirozynski and Weresub (1979). The specific epithet rhyniensis denotes the Rhynie chert collecting locality.

Fungi in Aglaophyton.-On the surface of Aglaophyton major axes (FIG. 1) are numerous, randomly distributed bulges that extend out 0.5-1.0 mm (FIG. 2). These bulges represent the sites of rhizoid development. Between the rhizoids, extramatrical hyphae enter the plant (FIGS. 3,8). There is no evidence that the fungus infects the plant by penetration of rhizoids. The fungus is present throughout the aerial axes and rhizomes except in the apices.

Extraradical hyphae.-The extramatrical mycelium consists of thick-walled, parallel hyphae that form almost cord-like units that contain up to five hyphae (FIGS. 4, 8). Hyphae infrequently branch and loops are formed in a few (FIG. 4). Hyphae in cords are normally nonseptate and range from 15 to $25 \mathrm{ixm}$ in diam. The hyphal wall is two-parted, consisting of an outer transparent layer and inner, more opaque zone (FIG. 5). The only structure that is suggestive of an appressorium (FIG. 6) shows an opaque swelling on the surface of the rhizoidal bulge situated immediately above a large, thick-walled intraradical hypha in the hypodermis. Some hyphae give rise to narrower, thinwalled branches that occasionally contain septations (FIG. 7). Both the bilayered wall and presence of septations are features also found in the extraradical hyphal phase of modern endophytes (Holley and Peterson, 1979; Bonfante-Fasolo, 1984).

The frequency of infection sites along the axes was difficult to determine due to the nature of the fossils and necessity of using thin section preparations. However, several hyphae can be seen entering the axis in a single section (FIG. 8) suggesting that the number 

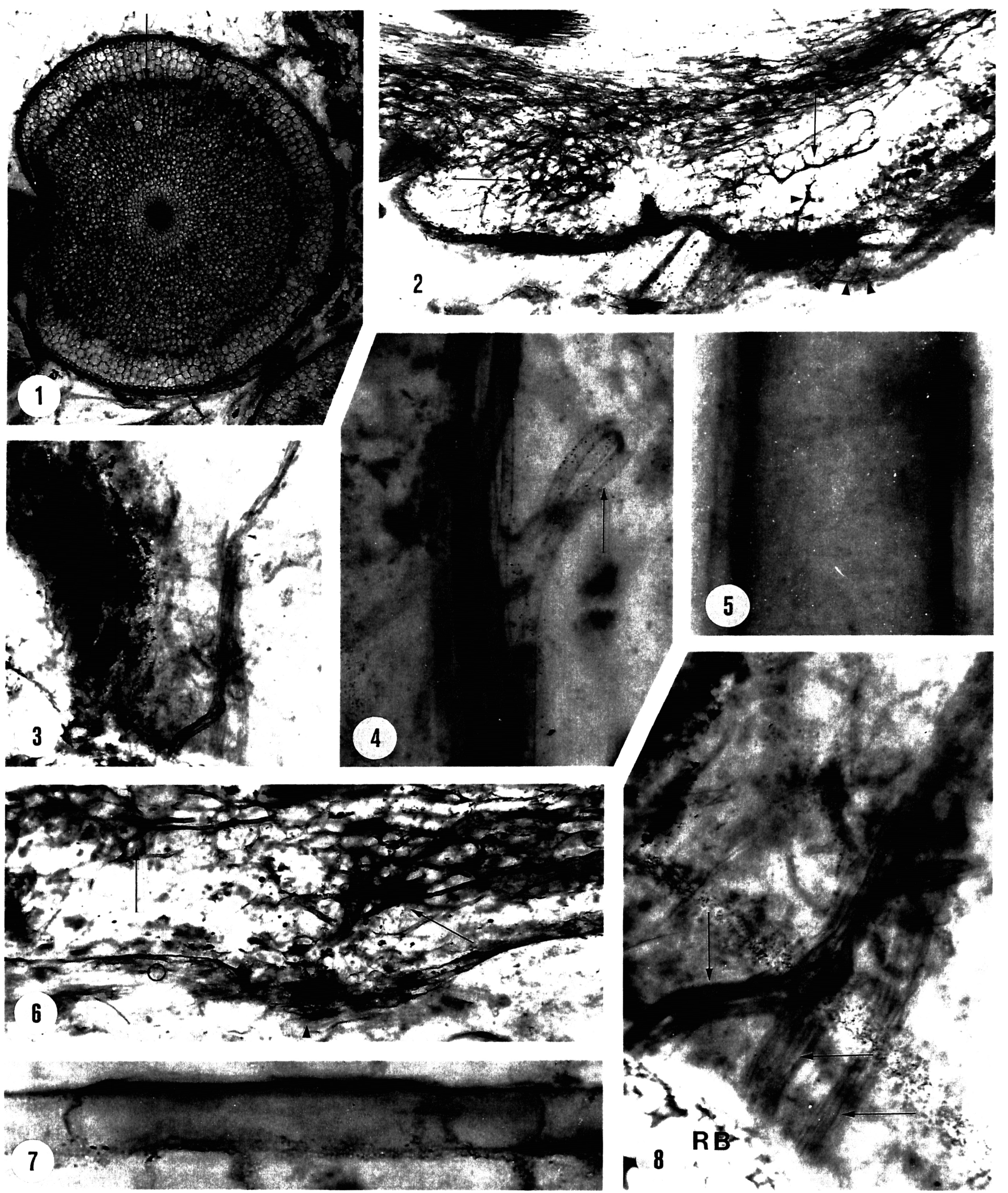

FIGS. 1-8. Fossil fungi and Aglaophyton major. 1. Transverse section of Aglaophyton major showing distribution of tissue systems. Arrow indicates the position of the arbuscule containing zone. Slide 1828, $x$ 15. 2. Partial section of Aglaophyton rhizome showing rhizoidal bulge. Note two aggregations of hyphae in hypodermis (arrows) and extraradical hypha penetrating axis (arrowheads). Slide $1385, x$ 25. 3. Extraradical bundle of hyphae at penetration point along axis. Slide 1384 , $x$ 40. 4 . Bundle of extraradical hyphae showing one hyphal loop (arrow). Slide 1384, x 200. 5. Extraradical hypha showing bilayered 
of infections was probably high. The fossil material provides no details regarding the nature of appressoria.

Intraradical phase-Axes of Aglaophyton consist of a cutinized uniseriate epidermis overlying a one- to fourcell-thick hypodermis (FIG. 10). To the inside of the hypodermis is the cortex, that includes a narrow outer layer (1-4 cells thick) and an inner zone of thin-walled cells with conspicuous intercellular spaces (FIG. 1). The structure and morphology of the intraradical mycelium is different, depending upon whether it occurs in the hypodermis or cortex.

In the hypodermis hyphae are thick-walled and highly branched (FIGS. 9, 11), with dichotomies occurring at acute angles, usually ranging from $30-60^{\circ}$. Hyphae range from 5 to $18 / \mathrm{im}$ in diam and are nonseptate. As a result of closely spaced and repeated dichotomies (60-18o /im apart), the rhizoidal bulges are often filled with the fungal mycelium (FIG. 2). Extending out from these thick-walled hyphal branches are narrow hyphae that sometimes branch at less acute angles. Some of these possess $\mathrm{H}$-shaped branches (FIG. 12). Hyphae of this type range from 8 to $14 / x m$ in diam and are extensively developed within the intercellular spaces of the cortex of both the aerial stems and rhizomes (FIGS. 13, 14). The hyphae are septate at this stage. There is no evidence of intracellular coils or the colonization of the axes by intracellular hyphae.

Spores.-Since we are uncertain as to how the structures that morphologically resemble chlamydospores and vesicles functioned in Glomites, we have adopted a neutral terminology and refer to them simply as spores. Spores resemble chlamydospores both morphologically and in the multilayered organization of the wall. Most spores occur in the inner cortical tissues of Aglaophyton (FIG. 15), although some may be present in the hypodermis. They vary from nearly elongate (FIG. 16) to globose (FIG. 17), and range from 50-80 Aim in diam. They are produced terminally, although in a few instances more than one spore is present at the end of a hypha (FIG. 17). In some regions, especially those with a high percentage of deteriorating arbuscules, a number of the spores are collapsed.

The spore wall is multilayered except at the point where the spore is attached to the hypha (FIGS. 16, 17). None show any evidence of septa at the base; rather the hypha is continuous with the inner spore wall layer (FIGS. 16, 17). The wall is bilayered and measures up to $6^{\wedge} \mathrm{m}$ thick, and consists of an outer, often translucent layer approximately 1 fim thick (FIG. 18). In some regions this layer is slightly separated from the inner wall (FIG. 19). This thicker (3-5 fim) inner layer is typically opaque, but in some very thin preparations several thin bands are evident in this zone of the wall (FIG. 19). As a result of the refractive properties of the chert matrix, it is not possible to define the organization or consistency of these layers.

Arbuscules.-The thin-walled intercellular hyphae that produce spores also give rise to branches that ultimately form arbuscule-like structures. In Aglaophyton, arbuscules are produced in a specific zone of thinwalled cells that delimits the outer edge of the cortex (FIGS. 1, 20). These cells are structurally distinct from other cells of the cortex by the smaller size, absence of large intercellular spaces and alignment in files (FIG. 39), suggesting that this zone remained meristematic for an extended period of time. Sections through this regions of the cortex are characterized by highly branched hyphae in the arbuscule zone (FIG. 24).

Cell penetration in extant arbuscular mycorrhizae takes place when hyphal branches exert pressure on the host cell wall and cause the plasmalemma to invaginate (Cox and Sanders, 1974). Hyphae in Aglaophyton that ultimately produce arbuscules are narrow ( $5 \mathrm{fim}$ ) and frequently occur along one of the larger intercellular hyphae (FIG. 21). These larger intercellular hyphae often have slightly flattened areas or angular projections that probably represent the sites of former arbuscule forming hyphae that have collapsed once arbuscles no longer function (FIG. 21). FIGURE 22 illustrates what we interpret as an immature hyphal branch extending between two cortical cells. As the hypha pushes between host cells, it becomes more elongate (FIG. 23), and subsequently extends through the cell wall. We have no stages that demonstrate the invagination of the plasmalemma during arbuscule formation in the fossil axes; all of the arbuscules appear either mature or in various stages of deterioration.

Penetration of the cortical cell by the arbusculeforming hypha may take place anywhere along the cell (FIGS. 25, 27). It is uncertain as to how many arbuscule trunks are produced from each intercellular hypha, since the nature of the fossil material makes it impossible to make closely spaced serial sections. In FIGURE

organization of wall. Compare with intraradical hypha wall in FIGS. 12 and 21. Slide 1384, x 2000. 6. Section of rhizoidal bulge at penetration point (arrowhead). Note well-developed hyphal aggregations in hypodermis (arrows). Slide 1382 . $x$ 40. 7. Hypha with septations. Slide 1702, x 1000. 8. Detail of hyphal penetration (arrows) in rhizoidal bulge (RB) between rhizoid clusters. Slide 1384, x 120. 

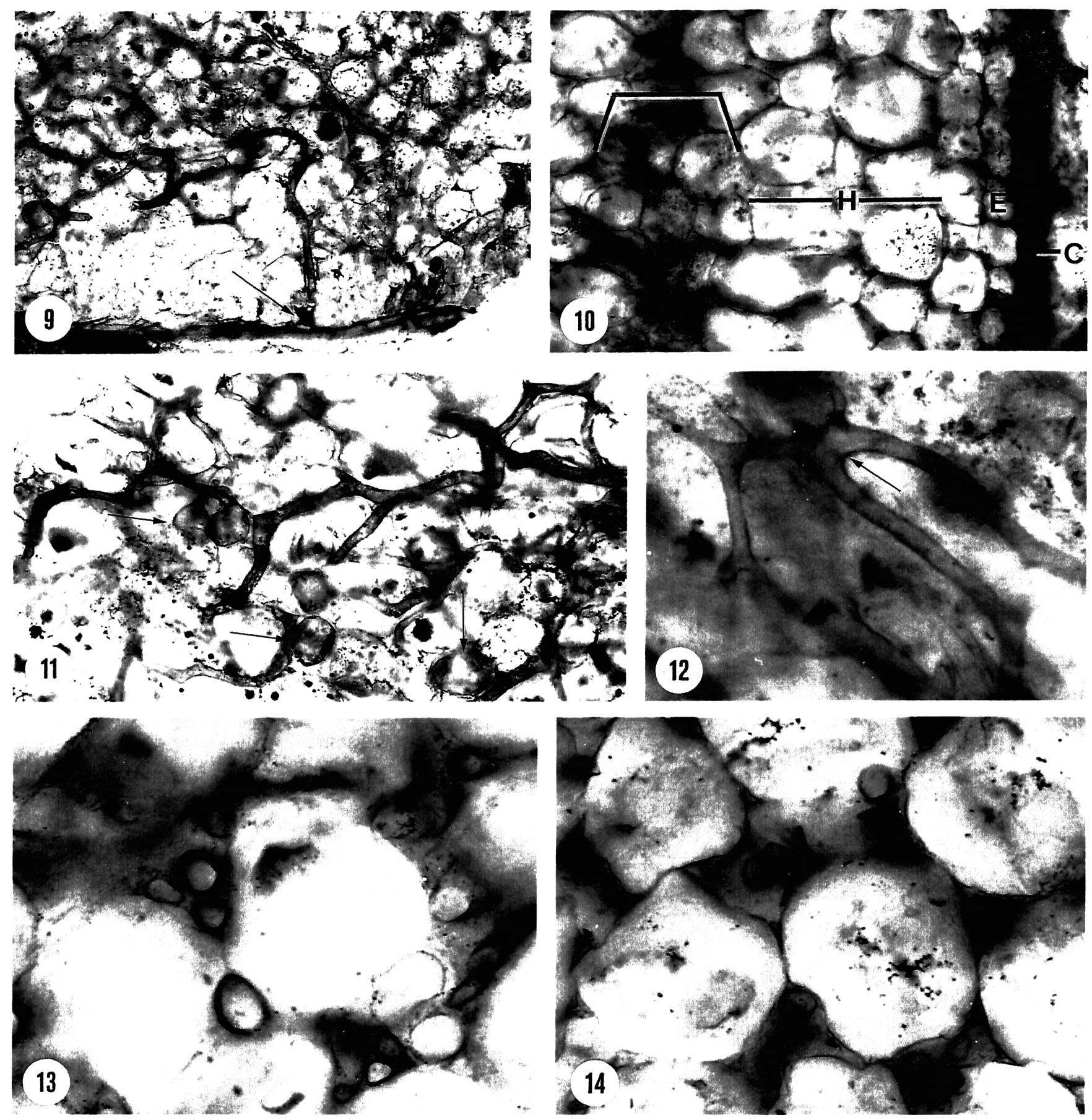

FIGS. 9-14. Glomites rhyniensis and Aglaophyton major. 9. Penetration point of hypha (arrow) and development in hypodermis. Slide 1407, x 75. 10. Partial transverse section of Aglaophyton major axis showing cuticle (C), epidermis (E), hypodermis (H) and zone of arbuscules (bracket). Slide 1828, x 125. 11. Intraradical hyphae illustrating extensive branching. Arrows illustrate a few spores. Slide 1407, x 120. 12. Detail of intraradical hyphae showing H-branching (arrow). Slide 1382 , $x 300.13$. Transverse section of rhizome cortex with numerous intercellular hyphae. Slide 1537, $x$ 500. 14. Transverse section of aerial stem cortex with numerous intercellular hyphae. Slide P.O. Nr., x 500 .

FIGS. 15-23. Glomites rhyniensis and Aglaophyton major. 15. Longitudinal section of Aglaophyton axis showing well-developed hyphae and numerous spores. Slide 1463, x 120. 16. Elongate spore; note continuity between inner spore wall and wall of hypha (arrow). Slide 1463, x 500. 17. Two spores arising from common hypha; note absence of septa. Slide 1463 , $x$ 500. 18. Detail of spore in FIG. 17 showing multilayered organization of wall. Slide 1463, $x 3000$. 19. Detail of spore wall in FIG. 16 showing outer separable layer. Slide 1463, x 2000. 20. Longitudinal section of Aglaophyton axis showing extensive arbuscule 

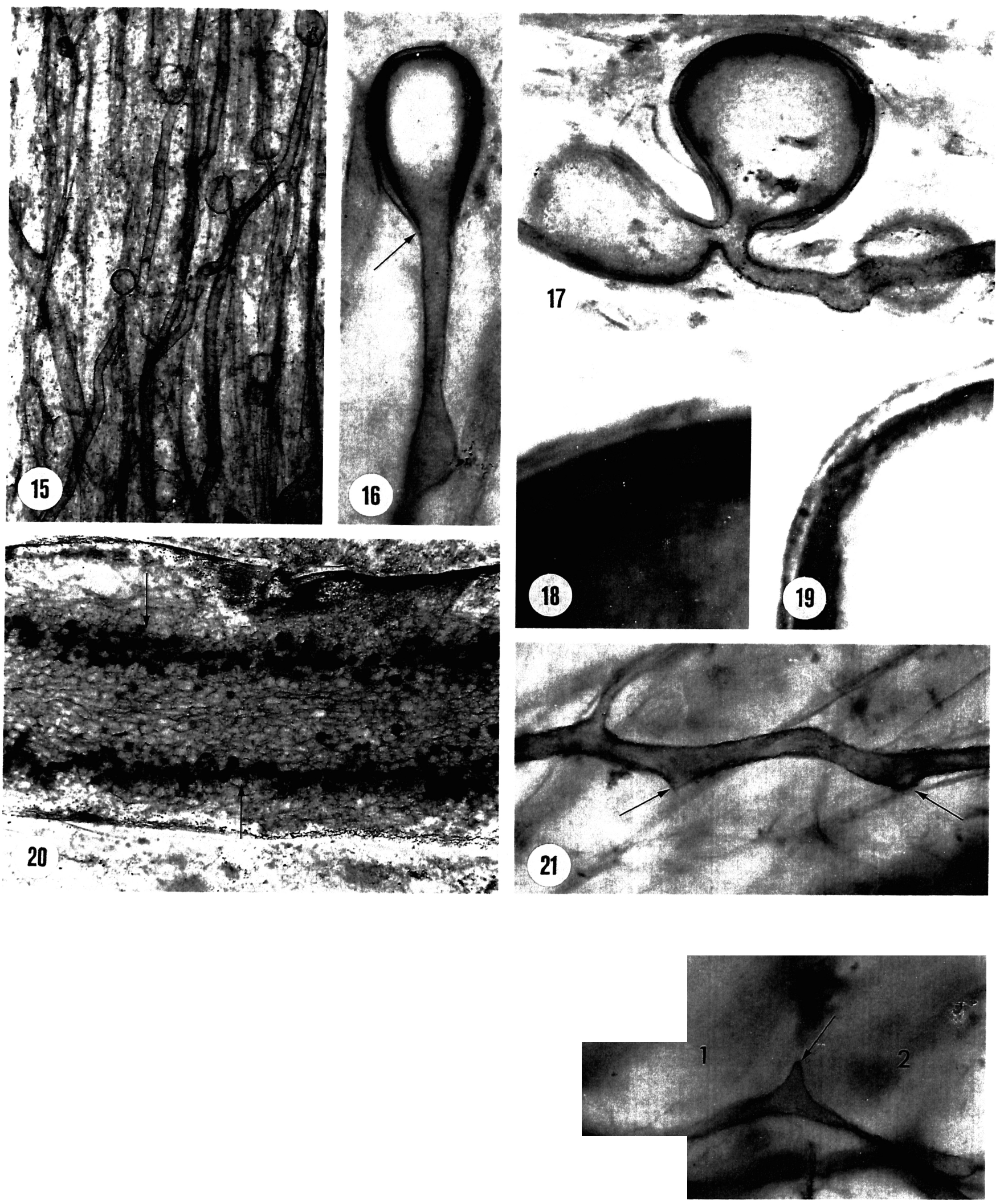

zone (arrows). Slide 2082, x 25. 21. Intraradical hypha giving rise to narrower branch that will ultimately penetrate a cell to form an arbuscule. Angular protrusions (arrows) indicate the former position of hyphal branches that have deteriorated. Slide 1652, x 400. 22. Three cortical cells (1-3) and intraradical hyphae (H). Arrow indicates branch beginning to extend between two cells. Slide 1702, x 800. 23. Two cortical cells $(1,2)$ with hyphal branch between (arrow). Slide 1384, x 400 . 
25, two adjacent cells each contain an arbuscule that clearly originates from the same intercellular hyphal branch. The trunk of the arbuscule is up to $3.5 \wedge^{\prime} m$ in diam and compares closely to the same intercellular hypha in size and wall thickness (FIG. 26). The host cell wall thickens slightly where the fungus penetrates the wall (FIG. 27). Cox and Sanders (1974) use the term collar to describe this host response in the cell wall, while stratified zone (Scannerini and Bellandon, 1968) and extrahaustorial matrix (Kaspari, 1973) are also used for the same host response. Inside the host cell, the arbuscule trunk dichotomizes repeatedly to form a dense aggregation that give the structure a bush-like appearance FIGS. 28, 31). Typically there is a single arbuscule per cell (FIG. 25), but a few cells appear to contain multiple arbuscules (FIG. 30) which is similar to the pattern in extant arbuscular mycorrhizae (Kinden and Brown, 1975 c). Sections through the top of the arbuscule suggest that the unit is divided into two to three major branches (FIGS. 29,32), with the smaller ultimate tips reduced to less than $0.5 / \mathrm{im}$ in diam. Often the distal ends of the arbuscule branches appear slightly swollen (approximately $1.5 \mathrm{~nm}$ in diam) (FIG. 35). Some branch tips are opaque, while others show an opaque collar that surrounds a translucent central area (FIG. 35). A few appear as if they bifurcate at the tip. Arbuscules that we interpret as mature fill approximately one third to one half of the cell lumen.

Many of the cortical cells appear to be filled with granular or opaque material (FIG. 30), and often the cells that contain them are partially collapsed. We interpret these as the remains of deteriorated arbuscules (FIG. 34), since they are similar to the amorphous mass that results when extant arbuscules deteriorate (Scannerini and Bonfante-Fasolo, 1983). A few of the bifurcating terminal hyphae also show signs of collapse (FIG. 36). AS more basipetal branches deteriorate, the arbuscule appears ill-defined (FIG. 30), probably as a result of the collapse of the trunk hypha (Kinden and Brown, 1975 b).

It is well known that in extant plants that other fungi may be present along with root endophytes (Nicolson, 1959), and this condition is also present in the fossil material. Some cortical cells contain structures that are morphologically comparable to arbuscules, but slightly larger, and less well organized (FIG. 38). Many of these show random branching and swollen tips (FIG. 37). In others the cell lumen appears packed with a fine mycelium. Although these cortical cell fungi occur associated with cells containing arbuscules, they represent mycoparasites that are now known to have been common in the Rhynie chert plants (Hass et al., 1994).

\section{DISCUSSION}

Aglaophyton major remains an enigmatic early land plant of which the systematic affinities are poorly defined. Historically, it has been regarded as a vascular plant, but recent studies suggest closer affinities with a bryophyte level of evolution. Thus, it is difficult to compare the spatial relationships of Glomites structures (hyphae, spores and arbuscules) as they relate to the cells and tissue systems of modern analogues. Endomycorrhizae have been reported in bryophytes (e.g., Gounet and Strullu, 1979) and pteridophytes (e.g., Boullard, 1979); however, the number of reports are relatively small. Bonfante-Fasolo (1984) indicates that mycorrhizae in cryptogams generally do not occur in the apices, cells of the endodermis, stele or gametangia. Where the fungus has infected the plant, root hairs often are rare.

The most comprehensive studies detailing the distribution of mycorrhizae in host tissue occur in flowering plants. Brundrett and Kendrick (1990) examined this relationship in several herbaceous angiosperms and found that features of the cortex, including cell size and shape, degree of cell suberinization, and the nature and type of cortical intercellular space, influence the penetration and distribution of the fungus within the host. In some hosts, endophyte colonization is greatly restricted within the cortical tissue, while in others the fungus shows no special preference for certain cell layers. For example, in Asarum roots that lack cortical air canals, hyphal colonization extends throughout the cortex with arbuscules forming near the center of the axis close to the endodermis and stele. In Smilacina roots, however, arbuscules form throughout the cortex except in cells that contain crystals. Still another pattern is illustrated in Trillium, where hyphae are restricted to the outer layers of the cortex and arbuscules are confined to a distinct layer just beneath.

The relationship between root anatomy and endophyte morphology may be categorized into several basic types (Gallaud, 1905). In the Arum series, cortical tissues possess well developed longitudinally oriented air passages that provide an easy method for fungal

FIGS. 24-31. Glomites rhyniensis. 24. Section of arbuscule containing zone showing relationship of intraradical hypha giving rise to branches (arrows) that ultimately form arbuscules (opaque spheres). Slide 2082, x 200. 25. Two common cell walls (arrow) of adjacent cells, each containing a single arbuscule. Note hyphal trunk extending into each cell to form an arbuscule. Slide $1827, \mathbf{x} 800$. 26. Detail of arbuscule showing large diameter of basal trunk (arrow) and relationship to cell wall. Slide $1703, \mathbf{x}$ 1300. 27. Corners of three cells (1-3) showing thickened apposition (arrow). Slide 1653, x 1300. 28. Well-developed 

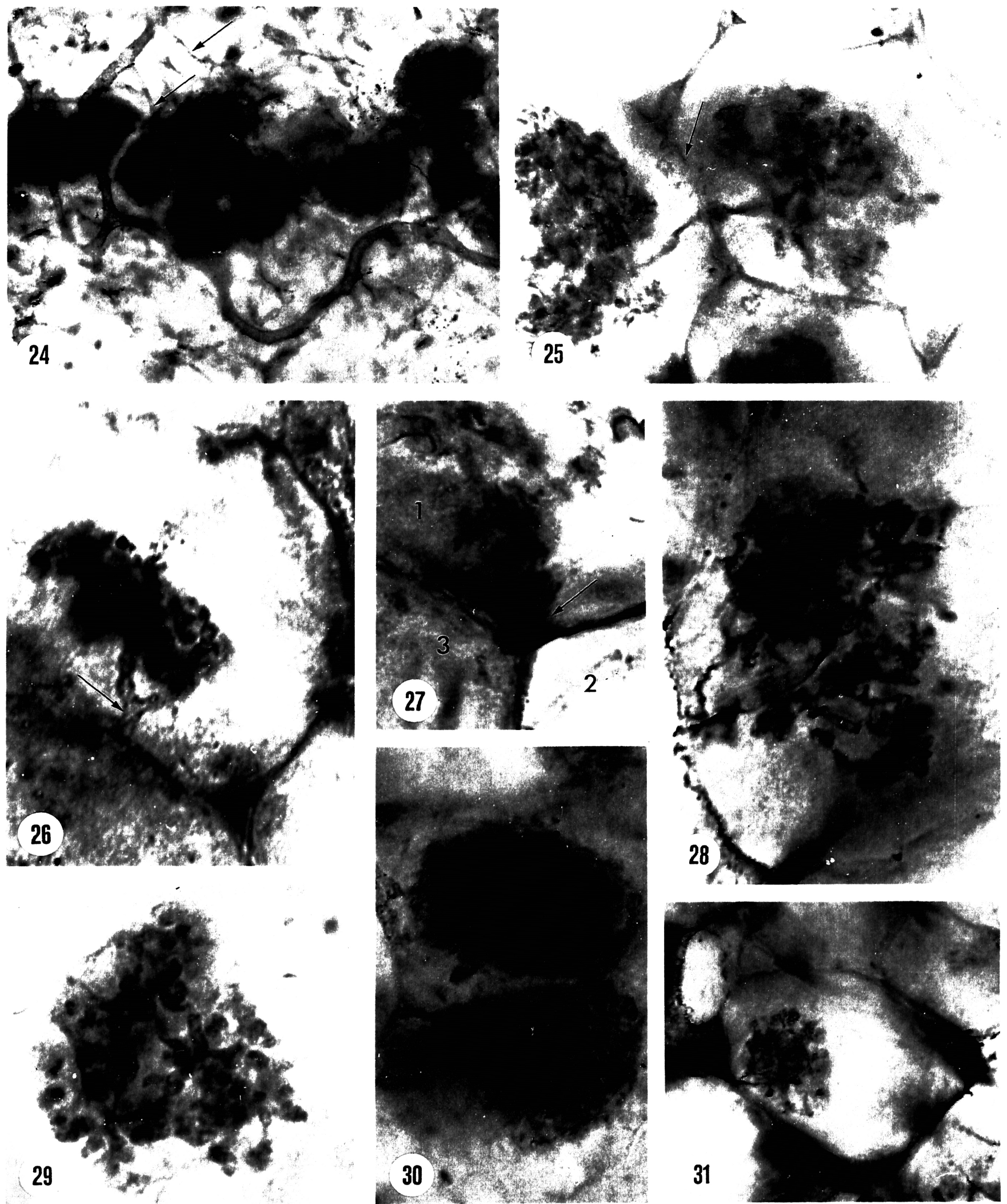

arbuscule showing highly branched organization of distal branches. Slide 1703, x 1500. 29. Distal view through mature arbuscule showing tips of some branches. Slide 1780, x 1300. 30. Two arbuscules within a common cell. Note disorganized arbuscule branches that are interpreted as stages of deterioration. Slide $1703, x 1000$. 31 . Cortical cell with small arbuscule. Slide 1703, x 600 . 
colonization. In the Paris series, hyphae are typically coiled and endophyte colonization takes place intracellularly. Aglaophyton clearly demonstrates the Arum series based on the extensive hyphal development that occurs within the intercellular spaces of the cortex (FIGS. 13, 14). If there is an evolutionary relationship between the endophyte and the anatomy of the absorbing organ, then the limited fossil evidence to date would support the Arum type as being basic.

There is considerable hyphal polymorphism in extant arbuscular mycorrhizae (Friese and Allen, 1991). For example, Powell (1976) reports that hyphae from Glomus spores germinated on agar plates buried in the soil were thick-walled, aseptate and rarely branched. As hyphae grew closer to roots there was a pronounced change in hyphal morphology resulting in septate, highly branched segments. These septate hyphae are believed to represent the initial phases of infection since they are generally absent when the endophytes are well established in the host (Powell, 1976). This same pattern of hyphal morphology is present in Glomites where aseptate and septate hyphae are found in close association. Moreover, the fossils also show evidence of small angular projections (FIG. 21) on some hyphae that have been interpreted as the sites of ephemeral, septate hyphae that have deteriorated (Powell, 1976). The variability in the size and branching pattern of the hyphae in Aglaophyton appears to be consistent with that found in extant arbuscular mycorrhizae (Abbott, 1982). Interestingly, Abbott and Robson (1979) suggest that the branching pattern in extant endophytes is not controlled by the age of the plant or phosphorus levels and, therefore, may have some taxonomic value.

In Aglaophyton cell type and organization of the tissue system also appears to greatly influence the distribution of the fungus. Penetration takes place between rhizoids where the cuticle or suberin layer is thin. Rarely are hyphae present in the hypodermis, except in the rhizoidal bulges because other cells of the axis are also heavily suberinized. Rather, development of the fungal colony occurs within the cortex. Arbuscules, however, only form in a narrow zone (one to four cell layers) of tightly compacted cells that lie just beneath the hypodermis. In extant plants cortical cells containing arbuscules revert to normal cell functions after the arbuscules deteriorate (Bonfante-Fasolo, 1984). In Aglaophyton, however, we hypothesize that as the cells that contained arbuscules deteriorated new cells were produced in which arbuscules could form. The presence of collapsed cells in this layer (FIG. 33) provides some additional support for this suggestion. There is, however, an obvious functional problem associated with this hypothesis as it relates to the large number of new cells required to accommodate Glomites arbuscules, especially if these exchange sites were as short-lived as those of extant endophytic biotrophs. Although the large number of deteriorated arbuscules in the fossil axes suggest these structures were shortlived, longevity of each arbuscule cannot be predicted. Rather, the possibility exists that they may have actually functioned as physiological exchange sites for an extended period of time. It is also important to underscore that within Aglaophyton axes there are a large number of arbuscules produced. Transverse and longitudinal sections illustrate that the arbuscule-containing zone forms a continuous cylinder throughout the axes. Within this zone most cells contain arbuscules. In certain extant plants, the degree of endophyte colonization appears to be specific for a given host (Brundrett and Kendrick, 1988). In Aglaophyton, perhaps the large number of arbuscules, together with a longer functional span, were unique features of this early endomycorrhizal system.

Despite an ever increasing data base of structural and morphological features of the Rhynie chert plants, we are only beginning to examine these organisms within the context of their environment. Few studies have addressed more physiological parameters in these organisms (e.g., Raven, 1977). The demonstration of arbuscular mycorrhizae in Aglaophyton may provide some additional information in this regard. In some living plants there appears to be a correlation between root and root hair development, and colonization by mycorrhizal fungi (Brundrett and Kendrick, 1988). Nonmycorrhizal plants possess well-formed roots with extensive root hair development, whereas in highly mycorrhizal plants, root hair development is less extensive. The rhizome of Aglaophyton is a structurally unique organ possessing stomata on all surfaces and rhizoidal bulges and conducting elements that are more similar to the leptoids and hydroids of bryophytes than they are to the tracheids of vascular plants. As a result of this anatomy, the rhizome of Aglaophyton may not have been a very efficient absorbing structure. This may, in part, explain the extensive development of

FIGS. 32-39. Glomites rhyniensis. 32. Section through distal region of arbuscule showing major dichotomy of trunk (arrow). Slide 1714, x 1500. 33. Two arbuscule containing cells $(1,2)$ flanked by two collapsed cells (arrows). Slide $1652, x 500.34$. Arbuscule in which the trunk (arrow) is intact, but distal branches are partially deteriorated (bracketed area). Slide 1779, $x$ 600. 35. Detail of arbuscule distal branches (arrows) showing organization and slightly swollen tips. Slide 1703, x 3000.36 . Arbuscule (A) with some distal tips collapsing. Slide 2004, x 500. 37. Mycoparasite in cortical cell of Aglaophyton. Compare 

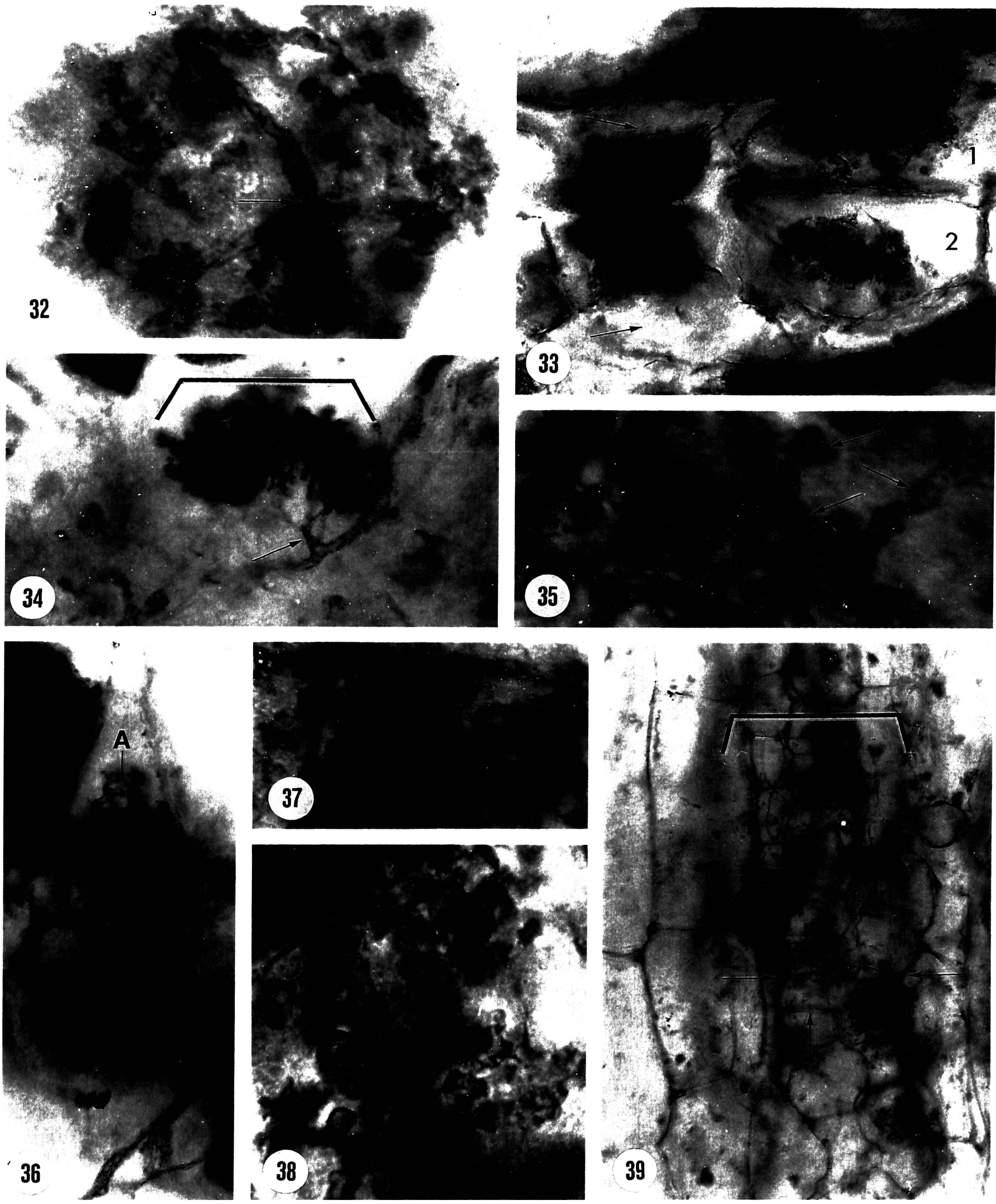

size difference with arbuscule tips in FIG. 35. Slide $1652, \mathbf{x} 1300.38$. Swollen structures represent probable mycoparasite in cortical cells. Slide 1652 , x 1300.39 . Longitudinal section of Aglaophyton axis through arbuscule containing region (bracket) showing linear files of cells (between arrows). Vertical arrow represents a recent cell division. Compare with transversely oriented files of FIG. 10. Slide 1702 , x 250 . 
Glomites arbuscules. Within the context of this scenario, the fungus would have been critical in both absorption and mineral exchange, especially in the nutrient poor substrate in which these plants are believed to have grown. Further attesting to the importance of the fungus in mineral absorption is the fact that Glomites occurs in all aerial parts of the plant, as well as in the rhizome. This may have been especially important since Aglaophyton lacked leaves and other photosynthesizing appendages.

Historically, the zygomycetes that formed arbuscular mutualistic symbioses were included with other fungi that possessed different nutritional modes in a single family, Endogonaceae (Gerdemann and Trappe, 1974). Pirozynski and Dalpe (1989) proposed the family Glomaceae to include two of the six extant genera, Glomus and Sclerocystis, as well as fossil hyphae, vesicles and spores that morphologically are comparable to those of extant mycorrhizal fungi. Recently, Morton and Benny (1990) proposed the Glomales as a new order to include all soil-borne fungi that form arbuscules in obligate mutualistic associations with terrestrial plants. Within this order are the families Glomaceae, Acaulosporaceae and Gigasporaceae, distinguished primarily by features associated with the production of spores (Morton, 1988; Morton and Benny, 1990). Despite the fact that several features used to define these families are not resolvable with the fossils, there can be little doubt that the fossil fungus described in this paper is a member of the Glomaceae as defined by Morton and Benny (1990).

Although there has been a continuing interest in arbuscular mycorrhizae, there has been little attempt to discuss these fungi within a phylogenetic context. Recently, Morton (1990b) analyzed 57 species of the Endogonaceae based principally on asexual spore characters. As a result of this cladistic analysis, two main branches were hypothesized to have evolved from a common arbuscule forming ancestor. One clade is defined by the production of intraradical vesicles in roots and includes Glomus. Within this group the most primitive forms are hypothesized as forming spores singly, or on a few hyphal branches (Morton, 1990b). Despite the fact that many of the characters used in this analysis are not applicable in dealing with the fossil, Glomites did produce solitary spores, and appears to have a multilayered spore wall like that of Glomus. Based on endogonaceous spore wall terminology of Walker (1983), the wall of Glomites appears most similar to the laminated type. In living endomycorrhizal fungi, the function of spores remains poorly understood. Most regard these spores as representing reproductive, storage or resting propagules. The large number of these structures in old axes of Aglaophyton suggests that they also may represent some type of resting structure. Other characters that suggest affinities with Glomus include the general size of the spores and hyphae, but these characters may be phenotypically variable and easily modified by environmental fluctuations (Morton and Benny, 1990; Morton, 1990a).

Of particular importance in relating Glomites to extant Glomus is the structure, and presumably function of the arbuscules. Arbuscule digestion in living mycorrhizae may be variable, but generally proceeds with the appearance of granular material at the terminal portion of the distal branches (Kinden and Brown, 1975 a). Stages are typically defined based on cytological features that are not available in the fossils. For example, Dexheimer et al. (1979) report that, when arbuscule branches collapse, they become encased in a fibrillar material of polysaccharides produced by the host cell. The fine granular material that is present in the fossils may represent a similar host response.

The large number of collapsed arbuscules observed in a single section of Aglaophyton is consistent with what would be expected based on the very ephemeral (4-6 days) nature of these structures (Cox and Tinker, 1976), and is in agreement with the pattern where an estimated $90 \%$ of the arbuscules are in various stages of deterioration (Kinden and Brown, 1975b). Other cells in the fossil arbuscule zone are shrunken and collapsed (FIG. 33). Intercellular hyphae associated with these cells are also partially collapsed, further suggesting that arbuscules have deteriorated.

In discussing the macro- and microevolutionary processes in extant Glomales, Morton (1990a) suggests that the most constant characters are those that possess developmental functions. Epigenetic constraints would be considerable relative to the arbuscules since they represent the critical interface between the host and fungus. This developmental stasis that is demonstrated by the fossil arbuscules not only strengthens the similarity between Glomites and Glomus, but also provides a strong basis for underscoring a functional homology as well.

The combination of characters shared by the fossil and extant specimens, indicates an ancient origin at least for lineages from Glomus. The only other structurally preserved fossil arbuscules come from the Triassic of Antarctica (Stubblefield et al., 1987). They occur in the roots of a cycad together with spores, vesiclelike structures, and intercellular and intracellular hyphae, some of which form coils. These arbuscules are much larger than those of Glomites, with the stalk up to $10 \mathrm{ixm}$ in diam, and ultimate branches in the 1.8 $\mathrm{Mm}$ size range. In general they are much coarser and therefore possess less surface area, and resemble those of Gigaspora (Morton, pers. comm.). Thus, while the basic dichotomously branched arbuscule organization 
appears to have been established early, the limited data from the fossil record might be interpreted as suggesting variation within the basic structure like that found in extant groups at the suborder level (Morton and Benny, 1990; Brundrett and Kendrick, 1990). Because the ontogenetic longevity of the fossil arbuscules can not be determined, it may be impossible to relate arbuscule number and morphology directly to function.

Until relatively recently, it was believed that plants became established on the land during Late Silurian. Rapidly accumulating evidence from several disciplines today suggests that the terrestrialization of plants may have occurred earlier, perhaps as early as the Ordovician. One widely promulgated hypothesis suggests that the colonization of the earth by land plants is a direct result of the establishment of an endomycorrhizal symbiosis (Jeffrey, 1962; Pirozynski and Malloch, 1975). According to this scenario land plants, either at a bryophytic or vascular plant level of organization, are a result of an ancient symbiosis between an aquatic green alga and fungus. While ideas about the initial partners in such a mutualism may have changed, the fundamental concept remains intriguing, especially as it relates to poor nutrient soils and the importance of the mycobiont. To a large degree, discovery of fungi in the Rhynie chert plants by Kidston and Lang (1921) provided the fossil evidence for this suggestion, although at the time of their writing the nutritional mode of these fungi was not understood. The Rhynie chert plants have historically been used to illustrate the structure and morphology of early land plants, principally because of the way they are preserved. Nevertheless they represent organisms that were significantly much younger geologically than the earliest land colonizers, perhaps by 75 million years if a mid Ordovician initial colonization date is used. In this regard it is perhaps not surprising that the Glomites endomycorrhiza is morphologically and structurally nearly identical to modern endophytic biotrophs like Glomus. Pirozynski and Dalpe (1989) have documented a number of glomalean spores and hyphae, some of which may be as old as the Cambrian. While the affinities and nutritional modes of some of these fossil fungi are problematic, the morphology of others suggests that Glomus-like fungi considerably predate the Rhynie chert arbuscular mycorrhizae. Our suggestion for the time of origin of these fungi is slightly older than the recently presented molecular data in which ribosomal DNA is analyzed from 12 species of extant arbuscular mycorrhizae spores (Simon et al., 1993). These authors suggest that arbuscular mycorrhizae evolved between 353-462 million yr ago, which is well within the 400 million year age of the Rhynie chert.
While the time of origin of this type of symbiosis and its role in the colonization by land plants remains conjectural, the Rhynie chert fungi show a potential to exert selective pressure on their host independent of the growth benefits of a mutualism. For example, certain extant hosts in the presence of modern endophytes increase the amount of vascular tissue as well as the lignification of the xylem (Daft and Okusanya, 1973). Perhaps the clusters of transfusion cells that characterize the rhizomes of Aglaophyton represent such a response. Some have used this host response to suggest that endophytes provided the initial stimulus in the lignification of cells during the evolution of vascular plants (Lewis, 1991). Finally, Wilson (1993) suggests that certain types of chemical plant defenses are the end product of initial endophyte infection, and these in turn have led to the revolutionary interrelationships between fungi and plants.

We may never be able to fully characterize the influence that fungal endophytes had on the evolution and establishment of the terrestrial ecosystem. Nevertheless, the demonstration that modern appearing endophytes existed at least 400 million years ago provides a critical source of information that must now accompany any discussion regarding the evolution of arbuscular fungi and their mycorrhizae.

\section{ACKNOWLEDGMENTS}

This study was completed during the tenure of a Senior U.S. Fellowship from the Von Humboldt Foundation awarded to the first author. Financial support from the National Science Foundation (OPP-9118314) and the Deutsche Forschungsgemeinschaft $(\operatorname{Re} 200 / 16-1,2)$ is gratefully acknowledged.

\section{LITERATURE CITED}

Abbott, L. K., and A. D. Robson. 1979. A quantitative study of the spores and anatomy of mycorrhizas formed by a species of Glomus, with reference to taxonomy. Aust. J. Bot. 27: 363-375.

Abbott, L. M. 1982. Comparative anatomy of vesiculararbuscular mycorrhizas formed on subterranean clover. Aust. J. Bot. 30: 485-499.

Ahmadjian, V. 1986. Symbiosis. University Press of New England, Hanover, New Hampshire. 212 pp.

Bonfante-Fasolo, P. 1984. Anatomy and morphology of mycorrhizae. Pp. 5-33. In: VA mycorrhizae. Eds., C. LI. Powell, and D. J. Bagyaraj. CRC Press, Boco Raton, Florida.

Boullard, B. 1979. Considerations sur la symbiose fongique chez les Pteridophytes. Syllogeus No. 19. Natl. Mus. Nat. Sci., Ottawa, Canada.

Brundrett, M. C., and B. Kendrick. 1988. The mycorrhizal status, root anatomy, and phenology of plants in the sugar maple forest. Canad. J. Bot. 66: 1153-1173. 
? and 1990. The roots and mycorrhizas of herbaceous woodland plants. II. Structural aspects of morphology. New Phytol. 114: 469-479.

Cox, G., and F. Sanders. 1974. Ultrastructure of the hostfungus interface in a vesicular-arbuscular mycorrhiza. New Phytol 73: 901-912.

, and P. B. Tinker. 1976. Translocation and transfer of nutrients in vesicular-arbuscular mycorrhizas. I. The arbuscule and phosphorus transfer: a quantitative ultrastructural study. New Phytol. 77: 371-378.

Cridland, A. A. 1962. Fungi in cordaitean roots. Mycologia 54: 230-234.

Daft, M.J., and B. O. Okusanya. 1973. Effects of Endogone mycorrhiza on plant growth. VI. Influence of infection on the anatomy and reproductive development in four hosts. New Phytol. 72: 1333-1339.

Dexheimer, J., S. Gianinazzi, and V. Gianinazzi-Pearson. 1979. Ultrastructural cytochemistry of the host-fungus interfaces in endomycorrhizal associations Glomus mosseae/AIlium cepa. Z. Pfianzenphysiol. 92: 191-206.

Edwards, D. S. 1986. Aglaophyton major, a non-vascular land plant from the Devonian Rhynie Chert. Bot.J. Linn. Soc. 93: 173-204.

Friese, C. F., and M. F. Allen. 1991. The spread of VA mycorrhizal fungal hyphae in the soil: inoculum types and external hyphal architecture. Mycologia 83: 409418.

Gallaud, I. 1905. Etudes sur les mycorrhizes endophytes. Rev Gen. Bot. 17:5-48, 66-83,123-136, 223-239,313$325,425-433,479-500$.

Gerdemann,J. W., and J. M. Trappe. 1974. Endogonaceae in the Pacific Northwest. Mycol. Mem. 5: 1-76.

Gourret, J. P., and D. S. Strullu. 1979. Etude cytophysiologique et ecologique des symbioses racinaires:nodules fixateurs d'azote et mycorhizes. Compte-Rendu Scientijique de IA.T.P. 28-20 CNRS Paris.

Halket, A. C. 1930. The rootlets of Ameylon radicans Will.; their anatomy, their apices, and their endophytic fungus. Ann. Bot. 44: 865-905.

Hass, H., T. N. Taylor, and W. Remy. 1994. Fungi from the Lower Devonian Rhynie chert: mycoparasitism. Amer. J. Bot. 81: 29-37.

Holley, J. D., and R. L. Peterson. 1979. Development of a vesicular-arbuscular mycorrhiza in bean roots. Canad. J. Bot. 57: 1960-1978.

Jeffrey, C. 1962. The origin and differentiation of the archegoniate land plants. Bot. Not. 115: 446-454.

Kaspari, H. 1973. Elektronenmikroskopische Untersuchung zur Feinstruktur der endotrophen Tabaqkmykorrhiza. Arch. Mikrobiol. 92: 201-207.

Kidston, R., and W. H. Lang. 1921. Old Red Sandstone plants showing structure, from the Rhynie Chert bed, Aberdeenshire. Part 5. The thallophyta occurring in the peat-bed; the succession of the plants throughout a vertical section of the bed, and the conditions of accumulation and preservation of the deposit. Trans. Roy. Soc. Edinburgh 52: 855-902.

Kinden, D. A., and M. F. Brown. 1975a. Electron microscopy of vesicular-arbuscular mycorrhizae of yellow poplar. I. Characterization of endophyte structures by scan- ning electron microscopy. Canad. J. Microbiol. 21: 989993.

, and 1975b. Electron microscopy of vesicular-arbuscular mycorrhizae of yellow poplar. IV. Hostendophyte interactions during arbuscular deterioration. Canad. I. Microbiol. 22: 64-75.

, and . 1975c. Electron microscopy of vesicular-arbuscular mycorrhizae of yellow poplar. III. Hostendophyte interactions during arbuscular development. Canad. J. Microbiol 21:1930-1939.

Lewis, D. H. 1991. Mutualistic symbioses in the origin and evolution of land plants. Pp. 288-300. In: Symbiosis as a source of evolutionary innovation. Eds., L. Margulis, and R. Fester. MIT Press, Cambridge, Massachusetts.

Malloch, D. W., K. A. Pirozynski, and P. H. Raven. 1980. Ecological and evolutionary significance of mycorrhizal symbioses in vascular plants (a review). Proc. Natl Acad. Sci. USA 77: 2113-2118.

Morton, J. B. 1988. Taxonomy of VA mycorrhizal fungi: classification, nomenclature, and identification. Mycotaxon 32: 267-324.

- 1990a. Species and clones of arbuscular mycorrhizal fungi (Glomales, Zygomycetes): their role in macro- and microevolutionary processes. Mycotaxon 37: 493515.

. 1990b. Evolutionary relationships among arbuscular mycorrhizal fungi in the Endogonaceae. Mycologia 82: 192-207.

, and G. L. Benny. 1990. Revised classification of arbuscular mycorrhizal fungi (Zygomycetes): a new order, Glomales, two new suborders, Glomineae and Gigasporineae, and two new families, Acaulosporaceae and Gigasporaceae, with an emendation of Glomaceae. $M y$ cotaxon 37: 471-491.

Nicolson, T. H. 1959. Mycorrhizae in the Gramineae I. Vesicular-arbuscular endophytes, with special reference to the external phase. Trans. Brit. Mycol Soc. 42: 421438.

1981. Palaeobotanical evidence for mycorrhizas. 13th Intl. Bot. Cong., Sydney, Australia, p. 187.

Osborn, T. G. B. 1909. The lateral roots of Ameylon radicans, Will., and their mycorrhiza. Ann. Bot. 23: 603611.

Peterson, R. L., and M. L. Farquhar. 1994. Mycorrhizasintegrated development between roots and fungi. $M y-$ cologia 86: 311-326.

Pirozynski, K. A., and Y. Dalpe. 1989. Geological history of the Glomaceae with particular reference to mycorrhizal symbiosis. Symbiosis 7: 1-36.

, and D. W. Malloch. 1975. The origin of land plants: a matter of mycoparasitism. BioSystems 6: 153-164.

, and L. K. Weresub. 1979. The classification and nomenclature of fossil fungi. Pp. 653-688. In: The whole fungus, the sexual-asexual synthesis. Vol. 2. Ed., B. Kendrick. Proc. 2nd Int. Mycol. Conf., Univ. Calgary, Kananaskis, Alberta. Natl. Mus. Nat. Sci., Natl. Mus. Canada and Kananaskis Foundation, Ottawa, Canada.

Powell, C. LI. 1976. Development of mycorrhizal infections from Endogone spores and infected root segments. Trans. Brit. Mycol Soc. 66: 439-445. 
Raven, J. A. 1977. The evolution of vascular land plants in relation to supracellular transport processes. Advances Bot. Res. 5: 153-219.

Remy, W., T. N. Taylor, H. Hass, and H. Kerp. 1994. 400 million year old vesicular arbuscular mycorrhizae (VAM). Proc. Nat. Acad. Sci. USA 91: 11841-11843.

Scannerini, S., and M. Bellando. 1968. Sullultrastruttura delle micorrize endotrofiche di Ornithogalum umbellatum L. inattivita vegetativa. Atti Accad. Sci. Torino CI. Sci. Fis. Mat. Nat. 102: 795-809.

, and P. Bonfante-Fasolo. 1983. Comparative ultrastructural analysis of mycorrhizal associations. Canad. J. Bot. 61: 917-943.

Sharma, B.D.,D. R.Bohra, and R. Harsh. 1993. Vesicular arbuscular mycorrhizae association in Lower Devonian plants of the Rhynie chert. Phytomorphology 43: 105110.

Simon, L., J. Bousquet, R. C. Levesque, and M. Lalonde.
1993. Origin and diversification of endomycorrhizal fungi and coincidence with vascular land plants. Nature 363: 67-69.

Stubblefield, S. P., T. N. Taylor, and J. M. Trappe. 1987. Vesicular-arbuscular mycorrhizae from the Triassic of Antarctica. Amer. J. Bot. 74: 1904-1911.

Trappe, J. M. 1987. Phylogenetic and ecological aspects of mycotrophy in the angiosperms from an evolutionary standpoint. Pp.5-25. In: Ecophysiology ofVA mycorrhizal plants. Ed., G. Safir. CRC Press, Boco Raton, Florida.

Wagner, C. W., and T. N. Taylor. 1984. Fungal chlamydospores from the Pennsylvanian of North America. Rev. Palaeobot. Palynol. 37:317-328.

Walker, C. 1983. Taxonomic concepts in the Endogonaceae: spore wall characteristics in species descriptions. Mycotaxon 18: 443-455.

Wilson, D. 1993. Fungal endophytes: out of sight but should not be out of mind. Oikos 68: 379-384. 